\title{
Proposal of an Efficiency Index for Supporting System Configuration Design
}

Nozomu Mishima, Keijiro Masui and Shinsuke Kondo at CE2007, San Jose Dos Campos, Brazil

Contents

$>$ Background: Microfactory

$>$ Necessity of system efficiency evaluation

$>$ Background: Total Performance Index (TPI)

$>$ Proposal of an efficiency index

$>$ Analysis of the test manufacturing process

$>$ Efficiency analysis of the microfactory

$>$ Discussion

$>$ Summary and future work 


\section{Background; Microfactory - purpose of development -}

\section{"Manufacturing system" is not a goal.}

$\checkmark \quad$ To fabricate a product, manufacturing system should be minimum.

$\checkmark$ Recently, demand of small and precise devices is increasing.

$\checkmark \quad$ Isn't it possible to manufacture small parts and products by small and simple manufacturing systems?

1. Develop a miniature manufacturing system consists of miniature machine tools and manipulators.

2. Prove the capability of the system throughout test production and efficiency analysis.

\section{Expected advantages}

$\checkmark \quad$ A small system can reduce energy, cost and space necessary for conventional factories. $\Rightarrow$ Lower Environmental Impact

$\checkmark \quad$ In a small system, system configuration can be changed easily. $\Rightarrow$ Higher Production Flexibility 


\section{Background; Microfactory}

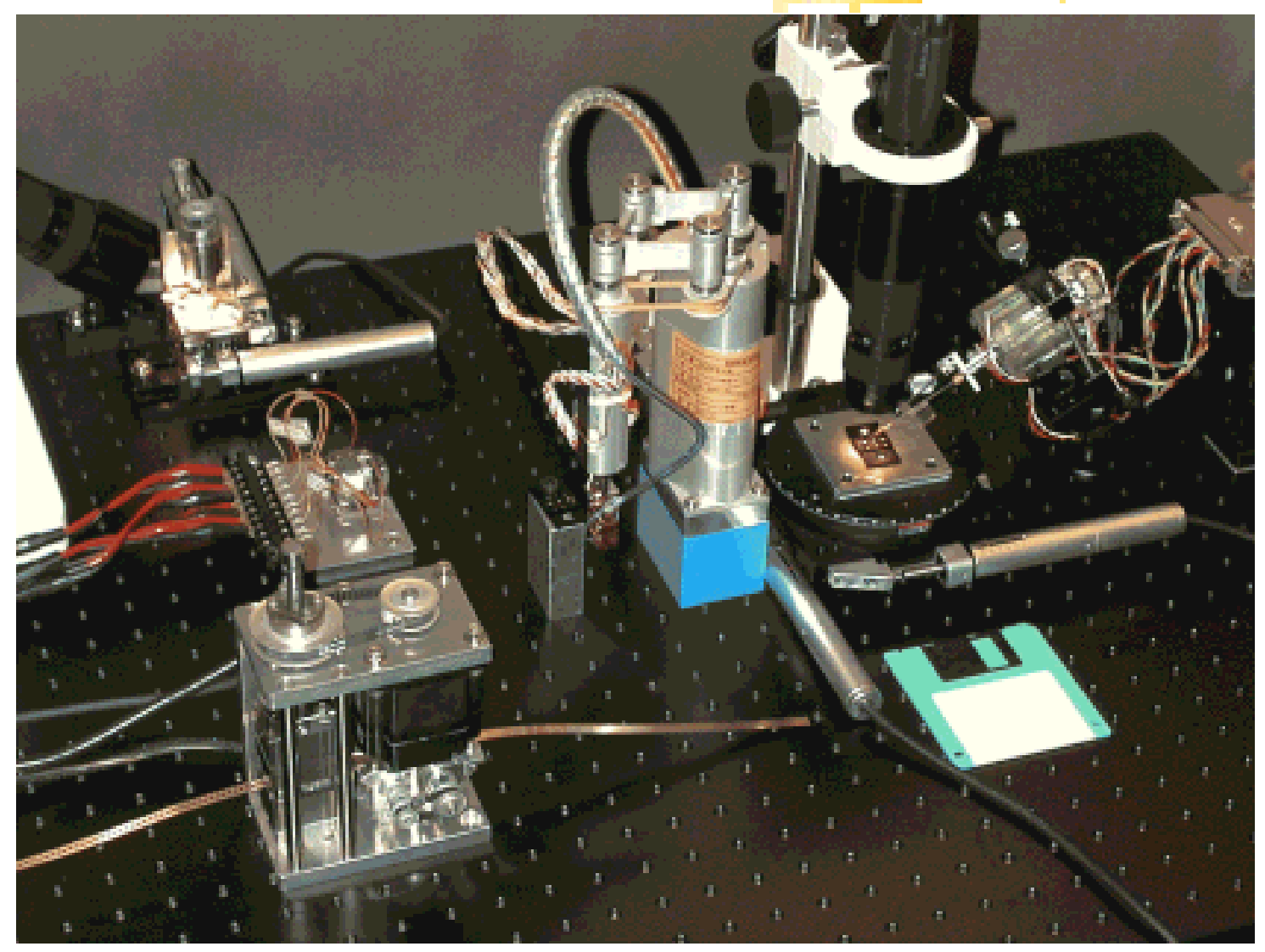

The world's first prototype of a desktop machining microfactory was developed in 1999 by AIST. It consisted of a lathe, a milling machine, a press machine, a transfer arm and a two-fingered micro hand.

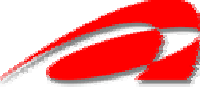




\section{Background; Microfactory}

- test product -

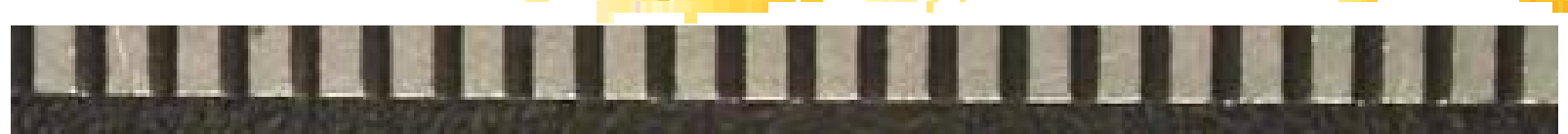

Assembled miniature bearing

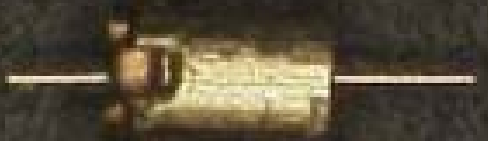

Rotary shaft

Top cover

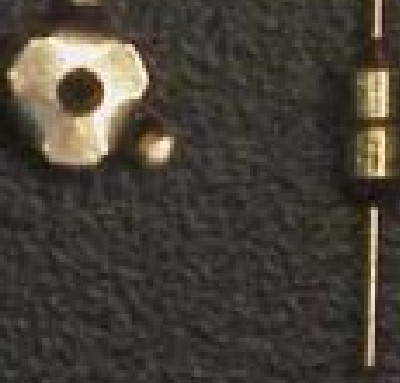

\section{Outer case}




\section{Necessity of system efficiency evaluation}

\section{Summary of the microfactory}

$\checkmark$ The prototyped microfactory showed the capability as a space-saving and energy-saving manufacturing system for small products.

$\checkmark$ Test production by the microfactory was successful. But, overall throughput of the system was low.

\section{Remained problems}

$\checkmark$ Although we insisted the advantage of the microfactory is capability of flexible configuration change, the effect has not been estimated.

$\checkmark$ To satisfy flexible production and low environmental impact simultaneously, estimation of these two factors is needed first.

$\checkmark$ Comparison between conventional system is necessary to insist that the microfactory is good for one-off or small-volume production.

$\Rightarrow$ Need to propose a system efficiency index of the microfactory. 


\section{Background; TPI - why necessary? -}

TPI (Total Performance Index) is an index to evaluate "real" performance of products, processes or systems.

Problems in existing evaluation tools

$\checkmark$ There is a lack of consideration about rise and fall of product values throughout the products' life cycle.

$\checkmark$ Most of the indexes do not evaluate environmental and economic performance at the same time.

(e.g. eco efficiency, environmental performance,value engineering for economic performance)

$\checkmark$ It is difficult for a designer to find out improvement targets in product design and its life cycle, based on the results of evaluation. 


\section{Background; TPI - definition of TPI -}

$$
T P I=\frac{U V}{\sqrt{L C E \cdot L C C}} \quad \begin{aligned}
& \text {-LCE: Environmental load throughout entire life } \\
& \text { cycle } \\
& \text { LCC: } \text { Life cycle cost }
\end{aligned}
$$

$>U V I L C C$ is a rather common index in quality engineering,

$>U V / L C E$ is the so-called eco-efficiency

Total Performance Index (TPI) :

Balance of a customer's utility value (UV) and its resulting environmental load and cost

UV is time integral of product value during its use stage and it can be calculated by weighed sum of functional requirements of the product. 


\section{Proposal of a system efficiency index}

What is "total performance" of manufacturing systems?

$$
\text { System TPI }=\frac{F}{\sqrt{C} \cdot \sqrt{E}}
$$

$F$ : system functionality, $C$ : total cost of the system during a certain period of time,

$E$ : environmental impact of the system during a certain period of time

$>F$ is sum total of product value manufactured in a certain time.

Definition of simplified system TPI

$$
T P I=\frac{T p}{\sqrt{C_{m}+C_{L}} \times \sqrt{E}}
$$

$T_{p}:$ System throughput (number of products/hour) $, C_{m}:$ Total machine cost (yen/hour), $C_{L}$ : labor cost (yen/hour), E: Environmental impact (CO2-kg)

$>$ When the product is always same, $F$ can be replaced by the system throughput. 


\section{Analysis of the test manufacturing process - model manufacturing process -}

Block diagram of the process used to produce miniature ball bearing assemblies by the microfactory

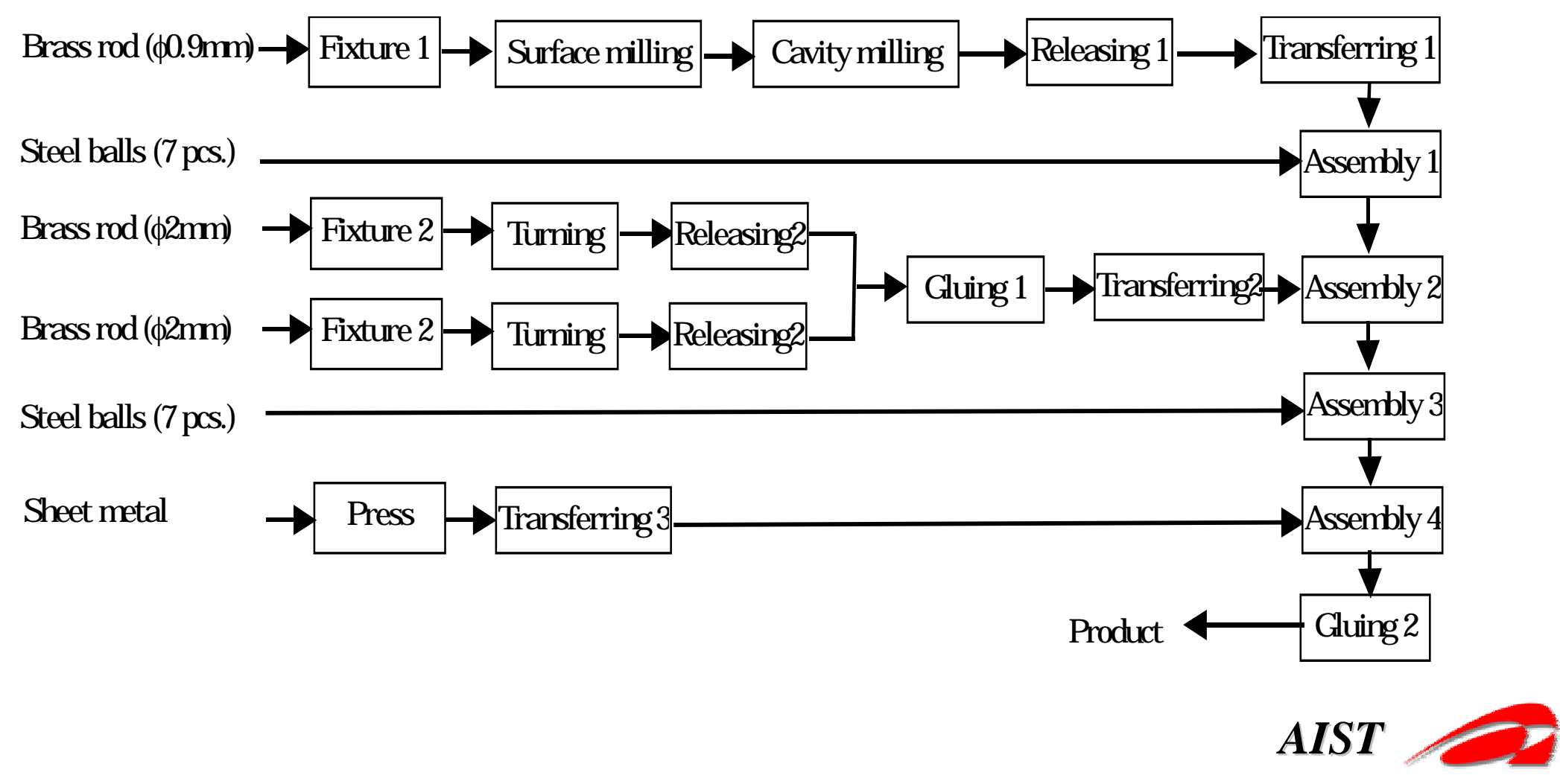




\section{Analysis of the test manufacturing process - process time for each sub-process -}

Analysis of the sub-processes base on the required average time

Required time and number of operators for each process /unit

\begin{tabular}{|c|c|c|}
\hline Process & Seconds & Operator \\
\hline Fixture 1 & $10 \mathrm{sec}$. & 1 \\
\hline Fixture 2 & $5 \mathrm{sec}$. & 1 \\
\hline Surface milling & $1 \mathrm{~min}$. & 1 \\
\hline Cavity milling & $2 \mathrm{~min}$. & 1 \\
\hline Turning & $2 \mathrm{~min}$. & 1 \\
\hline Press & $0.2 \mathrm{sec}$. & 0 \\
\hline Releasing 1 & $10 \mathrm{sec}$. & 1 \\
\hline Releasing 2 & $5 \mathrm{sec}$. & 1 \\
\hline
\end{tabular}

\begin{tabular}{|c|c|c|}
\hline Process & Seconds & Operator \\
\hline Transferring 1 & 1 sec. & 0 \\
\hline Transferring 2 & 1 sec. & 0 \\
\hline Transferring 3 & 1 sec. & 0 \\
\hline Assembly 1 & 3 min. (per ball) & 1 \\
\hline Assembly 2 & 3 min. & 1 \\
\hline Assembly 3 & 3 min. (per ball) & 1 \\
\hline Assembly 4 & 3 min. & 1 \\
\hline Gluing 1 & 1 min. & 1 \\
\hline Gluing 2 & 2 min. & 1 \\
\hline
\end{tabular}

The results showed that the assembly sub-processes are time consuming and the bottlenecks for the overall throughput. 


\section{Analysis of the test manufacturing process - cost and energy of machines -}

Analysis on the rough estimation of the initial cost of the machines and average power consumption

Machine costs
\begin{tabular}{|l|c|c|c|c|c|c|}
\hline Machine & Milling & Turning & Press & Arm & Hand \\
\hline Cost & 0.7 & 1.2 & 2.0 & 3.0 & 5.0 \\
\hline \multicolumn{7}{|c|}{ Energy consumption } \\
\hline Machine & Milling & Turning & Press & Arm & Hand \\
\hline Power(kw) & 0.25 & 0.3 & 0.05 & 0.2 & 0.4 \\
\hline
\end{tabular}

In this case, the two-fingered hand used for assembly is critical for the overall cost and energy consumption, too. 


\section{Analysis of the test manufacturing process}

$$
\text { - key device - }
$$

Assembly was the critical process for system throughput.

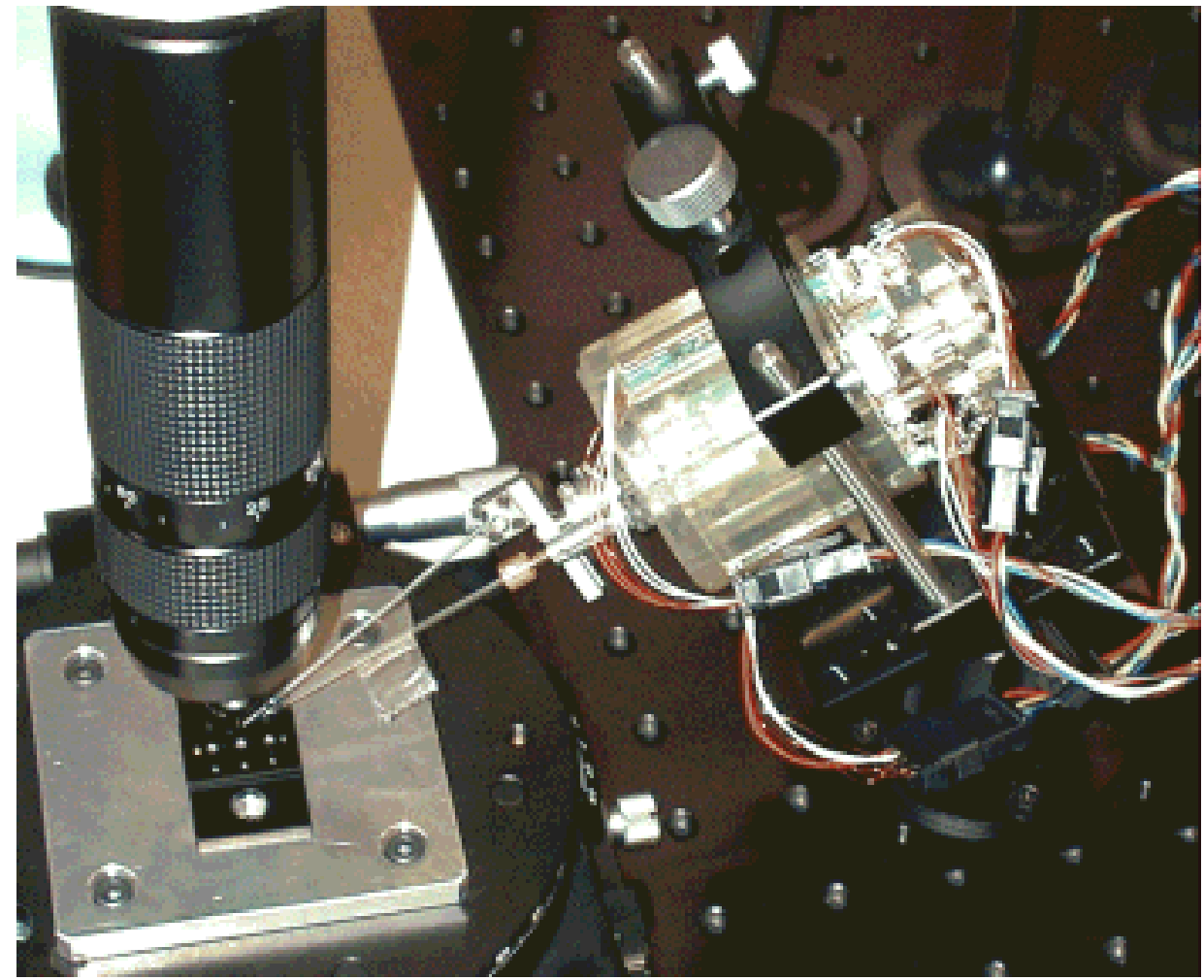

Dimensions: cylindrical hand $48 \mathrm{~mm}$ outer diameter, $65 \mathrm{~mm}$ high

(3 internal PZT actuators are used for each finger) Working range: approx. 100 $\times 100 \times 30 \mu \mathrm{m}$

Resolution of motion: $1 \mu \mathrm{m}$ or less

Object motion control: $200 \mu \mathrm{m}$ max.

Number of the "hand" will be a good variable to enhance throughput. 


\section{Efficiency analysis of the microfactory}

\section{system TPI of the microfactory}

$$
\begin{aligned}
& T P I=\frac{1.18 i}{\sqrt{(6.9+10 i+5) \times 10^{6} / 1600} \sqrt{(0.8+0.4 i) \times 0.38}} \quad(1 \leq i \leq 5) \\
& T P I=\frac{6.4 i}{\sqrt{(6.9+10 i+5) \times 10^{6} / 1600} \sqrt{(0.8+0.4 i) \times 0.38}} \quad(6 \leq i) \\
& T P I=\frac{1.18 i}{\sqrt{(5+10 i+5 j+1.2 k+0.7 l) \times 10^{6} / 1600} \sqrt{(0.25+0.4 i+0.3 k+0.25 l) \times 0.38}}
\end{aligned}
$$

TPI: system efficiency index (TPI) $i$ : number of hands and assembly operators

$j$ : number of machining operators $k$ : number of lathes, l: number of milling machines 


\section{Efficiency analysis of the system - behavior of the efficiency index -}

Deviation of the efficiency (system TPI) due to the change of the number of the two-fingered hand and assembly operators

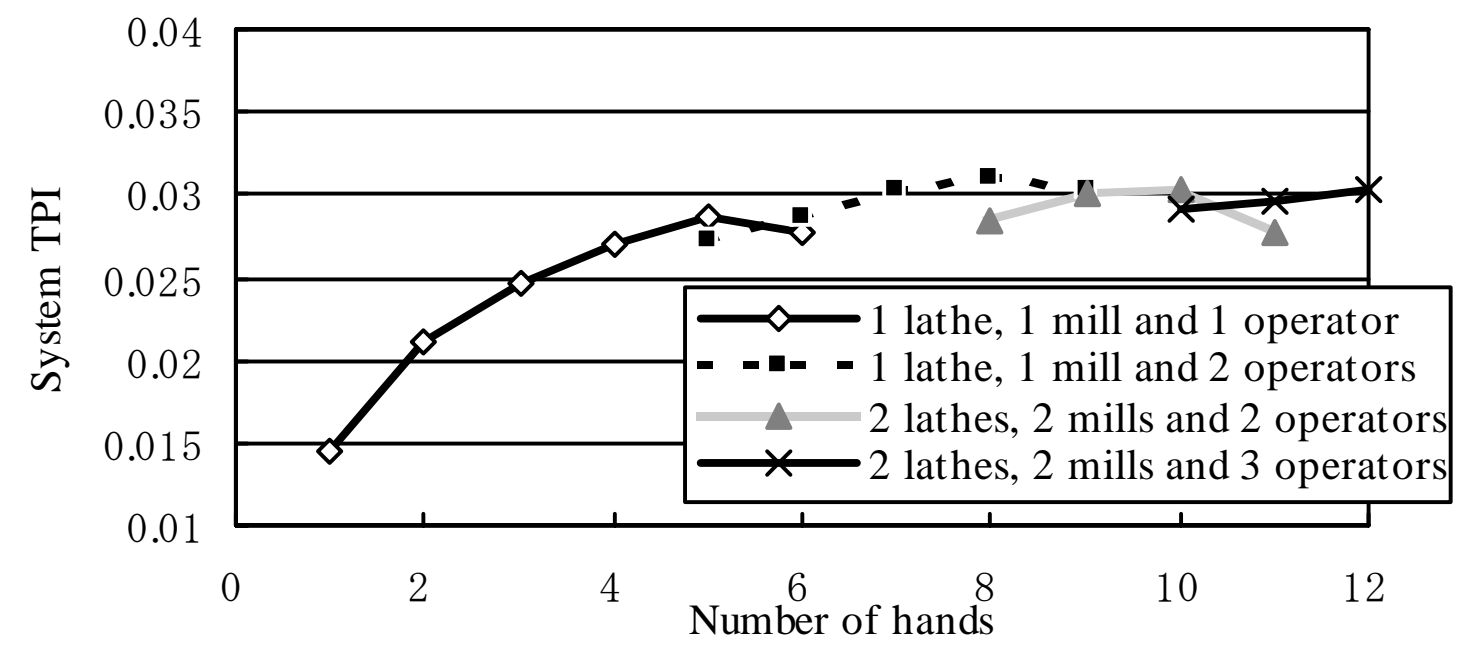

$\checkmark$ The figure shows that there are some local maximums.

$\checkmark$ Actual system configuration should be determined by the required throughput. 


\section{Discussion \\ - comparison with a mass production line -}

$\checkmark$ Typical manufacturing process for ball bearing is shown below.

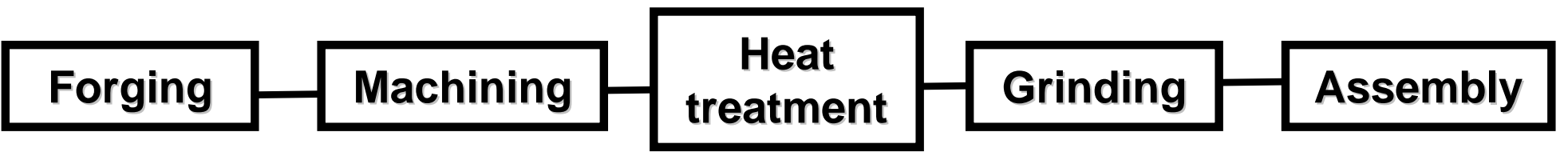

$\checkmark$ Data shows typical throughput of a mass production system is about 625 units per hour. Initial cost of the system is about 200 million yen and the power consumption is estimated to be about 200kw.

$\checkmark$ TPI of a mass production system can be calculated and compared.

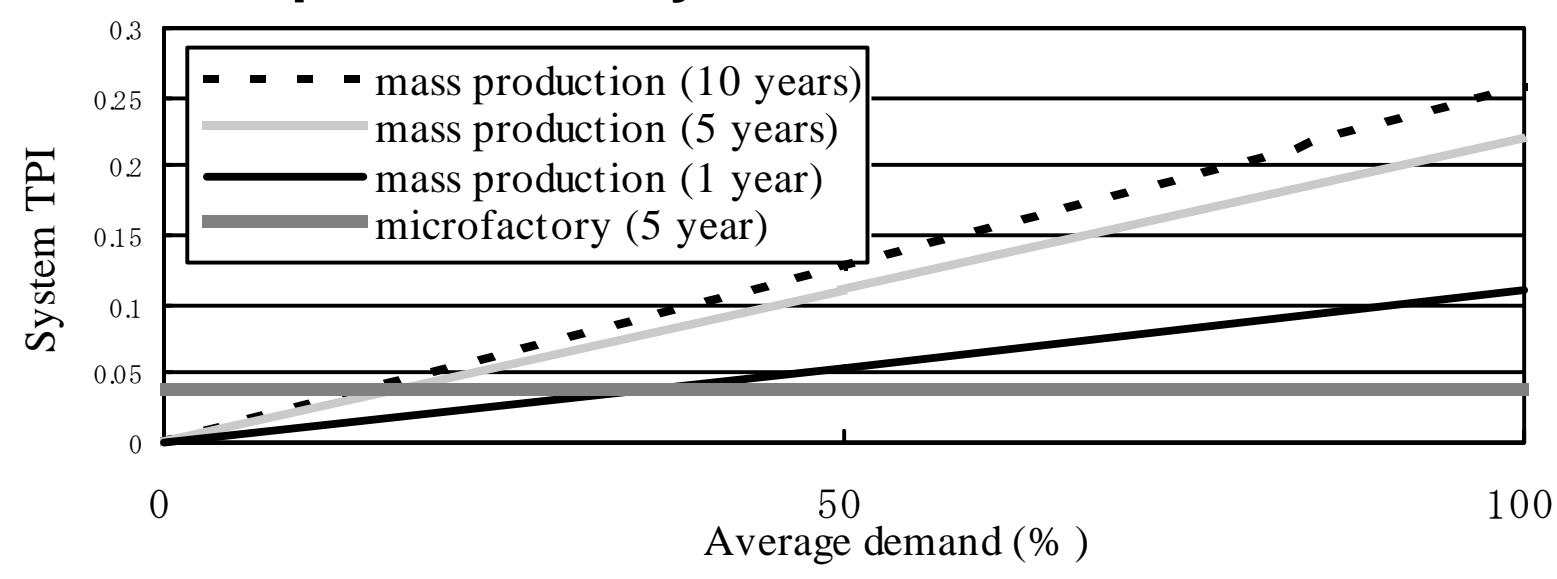




\section{Summary and Future work}

\section{Summary}

$\checkmark$ The microfactory showed significant capability for micro mechanical fabrication. As the next step, system efficiency index will be necessary. $\checkmark$ An index proposed to evaluate product performance (TPI) was applied to evaluate system efficiency, too.

$\checkmark$ The index ( system TPI) seemed useful in evaluating and supporting configuration design of microfactory-like systems.

$\checkmark$ System efficiency of the microfactory is not very low, when the lifetime of the system is relatively short and the demand is low.

\section{Future work}

$\checkmark$ Proposed efficiency index should be examined by evaluating more examples of conventional and micro manufacturing systems.

$\checkmark$ Robustness evaluation of systems against deviation of demand will be necessary. 